\title{
Evaluation of the efficacy and safety of topical timolol maleate combined with oral propranolol treatment for parotid mixed infantile hemangiomas
}

\author{
SHUANG TONG, DA-PENG XU, ZI-MEI LIU, YANG DU and XU-KAI WANG \\ Department of Oral and Maxillofacial Surgery, School of Stomatology, China Medical University, \\ Liaoning Institute of Dental Research, Shenyang, Liaoning 110002, P.R. China
}

Received March 20, 2015; Accepted April 8, 2016

DOI: $10.3892 / \mathrm{ol} .2016 .4818$

\begin{abstract}
The aim of the present study was to assess the efficacy and safety of topical timolol maleate combined with oral propranolol for parotid infantile hemangiomas. Between October 2012 and April 2014, propranolol was administered orally at a dose of $1.0-1.5 \mathrm{mg} / \mathrm{kg} /$ day to 22 infants with proliferating hemangiomas in the Department of Oral and Maxillofacial Surgery (Hospital of Stomatology, China Medical University, Shenyang, Liaoning, China). A small amount of $0.5 \%$ timolol maleate eye drop solution was topically applied with medical cotton swabs to the area of the lesion twice a day, every $12 \mathrm{~h}$. The study group consisted of 9 males and 13 females, aged 2-9 months, with a median age of 4.7 months. The lesions were all located in the parotid region, and measured between $3.5 \times 4 \times 0.5$ and $7 \times 8 \times 3 \mathrm{~cm}$ in volume. The planned duration of therapy was 6-8 months, or the two drugs were stopped when complete regression of the lesions was obtained. The therapeutic outcomes and safety were assessed by the change in the size and color of the tumor, and the presence of adverse effects throughout the course of treatment. The mean duration of therapy was 21.1 weeks and ranged from 3 to 8 months. Of the 22 patients, 16 demonstrated an excellent response, 6 showed a good response and 2 displayed a moderate response. No major collateral effects were observed. Overall, oral propranolol combined with topical timolol maleate may be used as the first-line therapeutic choice in the treatment of infantile parotid mixed hemangioma.
\end{abstract}

\section{Introduction}

Infantile hemangiomas (IHs) are the most common tumors of infancy and childhood, with an incidence of $2-3 \%$ in

Correspondence to: Professor Xu-Kai Wang, Department of Oral and Maxillofacial Surgery, School of Stomatology, China Medical University, Liaoning Institute of Dental Research, 117 Nan Jing North Street, Heping, Shenyang, Liaoning 110002, P.R. China

E-mail: wangxukai757892@sina.com

Key words: parotid, infantile hemangiomas, timolol maleate, propranolol the neonate, $10 \%$ in the baby after 1 year and up to $23 \%$ in premature infants, with a slight female predominance (1). Hemangiomas are characterized pathologically by endothelial cell hyperproliferation and may be divided into the following three types, according to the depth of their locations: Superficial hemangioma located in the papillary dermis, deep hemangioma located in the reticular dermis and subcutaneous tissue, and mixed hemangioma, which is a mixture of superficial and deep components (2). Deep hemangiomas present as blue or colorless masses, whereas superficial hemangiomas often present as bright red lesions (2). Blood flow in hemangiomas can be observed by ultrasonography. The disease is self-limiting, which often occurs in the neonatal period, and then enters the proliferative phase, stops development around the age of 1 and begins to regress $(3,4)$. Parotid hemangioma is the most common type of salivary gland hemangioma in children. Complications of this condition may include ulceration, life-threatening airway obstruction and the risk of delayed language acquisition due to ear involvement. Patients should therefore be treated as soon a possible (5). A number of clinical studies have shown that propranolol is usually highly effective for deep hemangiomas and that timolol maleate is usually highly effective for superficial lesions (6). The present study reports the application of topical timolol maleate combined with oral propranolol for parotid IHs in the Department of Oral and Maxillofacial Surgery (Hospital of Stomatology, China Medical University, Shenyang, Liaoning, China), resulting in a clear curative effect.

\section{Patients and methods}

Patients. In total, 22 patients with mixed-type parotid gland proliferating hemangioma were treated with topical timolol maleate combined with oral propranolol between October 2012 and April 2014 at the Department of Oral and Maxillofacial Surgery in the Hospital of Stomatology (Table I). The group consisted of 9 boys and 13 girls, with a mean age of 4.7 months (range, 2-9 months). The volume of these tumors varied between $3.5 \times 4 \times 0.5$ and $7 \times 8 \times 3 \mathrm{~cm}$, as measured by Doppler ultrasonography (Philips iU22 Cart F 4D ultrasound system; Philips Electronics Japan, Ltd., Tokyo Japan). The diagnosis of 
hemangioma was made based on the medical history (age of onset), clinical presentations and Doppler ultrasonography: A mixture of superficial and deep components were observed and blood flow in the hemangiomas was identified by ultrasonography. Data was collected from patient files, including clinical characteristics, efficacy of treatment and adverse reactions. The inclusion criteria for this study were as follows: i) No infants were administered any treatment prior to propranolol and timolol maleate.; ii) any other vascular malformations were excluded, according to the classification and nomenclature of vascular anomalies proposed by Waner and Suen (7); and iii) normal chest X-ray, electrocardiogram, blood coagulation, liver function, renal function and blood routine examination results. The Ethical Review Board of China Medical University approved the study and the parents of all infants provided written informed consent for publication.

Treatment protocol. All patients were admitted to the hospital when the hemangiomas were in the rapidly proliferating phase. Propranolol $(10 \mathrm{mg} /$ tablet; Tianjin Lisheng Pharmaceutical Co. Ltd., Tianjin, China) was prepared from a tablet into a suitable solution at a single oral dose of $1.0-1.5 \mathrm{mg} / \mathrm{kg} / \mathrm{day}(1.0 \mathrm{mg} / \mathrm{kg}$ for patients $<3$ months old and $1.5 \mathrm{mg} / \mathrm{kg}$ for patients $>3$ months old). A small amount of $0.5 \%$ timolol maleate eye drop solution $(25 \mathrm{mg} / 5 \mathrm{ml}$; Wuhan Five King Pharmaceutical Co., Ltd., Wuhan, Hubei, China) was also topically applied with medical cotton swabs to the area of the lesion twice a day, every $12 \mathrm{~h}$. For the first 3-5 days of management, heart rate, blood pressure and blood glucose levels were monitored in the inpatient ward. The patients who experienced no adverse reactions were topically administered the drug by their parents or guardians following discharge from the hospital. Close observation was paid to the heart rate, blood pressure and other vital signs during the treatment, and the parents were informed to look for local redness and symptoms such as a loss of appetite, nausea, vomiting, wheezing, shortness of breath or lethargy. Once any symptom appeared, the drugs were stopped immediately and the patient observed carefully. The patients were reexamined periodically in order to observe the size and color of the hemangiomas for assessment of the curative effect. The dose of the drug was altered according to the change in the weight of the patient and the degree of adverse reaction at the period of follow-up. Treatment was continued until 1 year old, unless complete resolution occurred (8). The follow-up timeline ranged from 1-10 months (median, 6.4 months).

Evaluation of efficacy. The therapeutic outcome was evaluated by Doppler ultrasonography. The results were measured by the hemisphere measurement and visual changes on photography (9). The clinical effect of treatment was graded on a 4-point scale proposed by Achauer et al (10), based on improvements in tumor volume, color and texture after treatment, as follows: I (poor), tumor volume decreased by $<25 \%$; II (moderate), tumor volume decreased by $26-50 \%$; III (good), tumor volume decreased by $51-75 \%$; and IV (excellent), tumor volume decreased by $76-100 \%$.

With regard to safety, heart rate, systolic blood pressure (SBP), diastolic blood pressure (DBP) and blood glucose level were close monitored in the course of the 3-day hospitalization
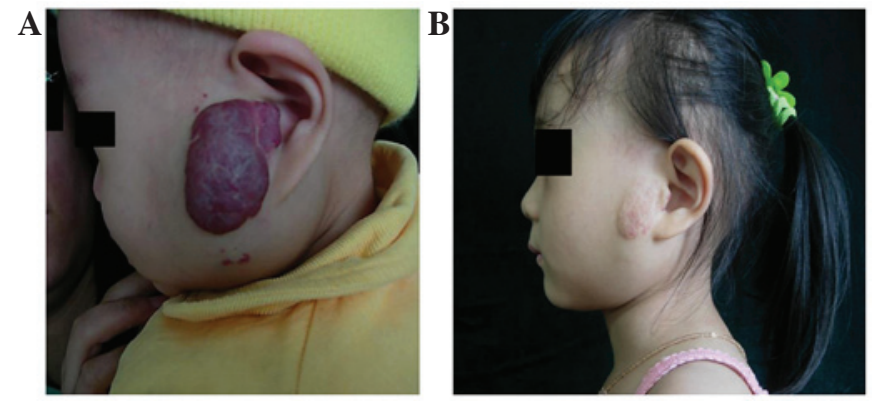

Figure 1. A pediatric patient (patient no. 6) with an infantile hemangioma in the left parotid area at (A) 6 months of age, prior to treatment, and (B) at 4 years of age, 28 weeks after topical timolol maleate combined with oral propranolol treatment. The coloration of the tumor was markedly decreased.
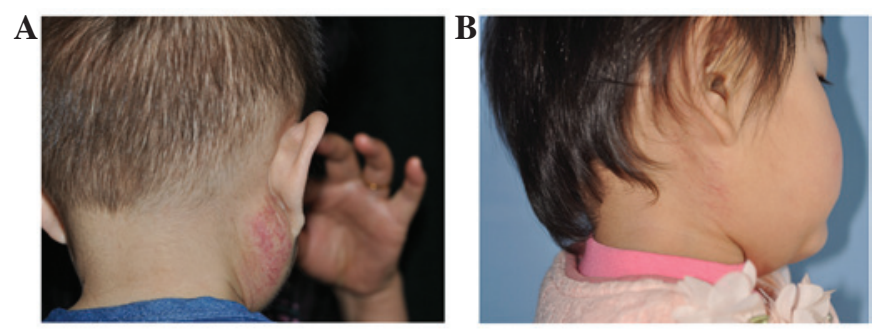

Figure 2. An 8-month-old girl with a infantile hemangioma in the right parotid area (A) prior to treatment and (B) at 4 years of age, 20 weeks after topical timolol maleate combined with oral propranolol treatment. The tumor completely disappeared.

period and were recorded $1 \mathrm{~h}$ after each dose. Local side effects, including rashes, red spots, erosion and ulceration, were also closely observed.

Statistical analysis. All data was entered into a database and processed using SPSS software (version 18.0; SPSS Inc., Chicago, IL, USA). The Kruskal-Wallis test was used to compare the differences in the average heart rate, SBP and DBP prior to and following drug administration. $\mathrm{P}<0.05$ was used to indicate a statistically significant difference.

\section{Results}

All the hemangiomas decreased in size following treatment and in the majority of cases, the tumor color changed from bright red to dull red. Efficacy scores was evaluated as follows: IV (excellent), 14 cases (64\%); III (good), 6 cases (27\%); II (moderate), 2 cases (9\%); and I (poor), 0 cases $(0 \%)$. The parents were quite satisfied with the results. At $24 \mathrm{~h}$ post-medication, the tension of the tumor surface of the majority of children decreased and the texture became softer. In total, the drug was administered for 12 weeks in 3 patients, for 16 weeks in 5 patients, for 20 weeks in 4 patients, for 24 weeks in 5 patients, for 28 weeks in 3 patients and for 32 weeks in 2 patients, with a mean time of 21.1 weeks. The tumor of 1 patient regressed completely following 16 weeks of treatment. However, the tumor had relapsed when the infant was followed up 6 weeks later and the proliferation was subsequently effectively controlled by the continuation of medication for $\sim 10$ weeks after treatment, until it decreased in size. Typical cases are shown in Figs. 1 and 2. 
Table I. Summary of treatment of IHs with topical timolol maleate combined with oral propranolol.

\begin{tabular}{|c|c|c|c|c|c|c|c|c|}
\hline $\begin{array}{l}\text { Patient } \\
\text { no. }\end{array}$ & Gender & $\begin{array}{c}\text { Age at } \\
\text { treatment } \\
\text { onset, months }\end{array}$ & $\begin{array}{c}\text { Treatment } \\
\text { duration, } \\
\text { weeks }\end{array}$ & $\begin{array}{l}\text { Size of IH prior } \\
\text { to treatment, } \mathrm{cm}^{\mathrm{a}}\end{array}$ & $\begin{array}{l}\text { Size of IH after } \\
\text { treatment, } \mathrm{cm}^{\mathrm{a}}\end{array}$ & $\begin{array}{c}\text { Side } \\
\text { effects }\end{array}$ & $\begin{array}{l}\text { Follow-up, } \\
\text { months }\end{array}$ & Response \\
\hline 1 & $\mathrm{~F}$ & 3 & 20 & $2.5 / 2 / 0.5$ & $0 / 0 / 0$ & None & 6 & Excellent \\
\hline 2 & M & 3 & 24 & $8 / 7 / 3$ & $0 / 0 / 0$ & None & 6 & Excellent \\
\hline 3 & M & 2 & 24 & $4 / 3.5 / 1$ & $0 / 0 / 0$ & None & 10 & Excellent \\
\hline 4 & $\mathrm{~F}$ & 3 & 16 & $3.5 / 3 / 0.5$ & $1 / 1.5 / 0$ & None & 9 & Good \\
\hline 5 & M & 7 & 16 & $3 / 4 / 1.5$ & $1 / 0.5 / 0$ & Diarrhea & 8 & Good \\
\hline 6 & $\mathrm{~F}$ & 6 & 28 & $7 / 6.5 / 2$ & $0 / 0 / 0.5$ & None & 10 & Excellent \\
\hline 7 & $\mathrm{~F}$ & 2.5 & 12 & $1.5 / 1 / 0.5$ & $0.5 / 0 / 0$ & None & 12 & Excellent \\
\hline 8 & $\mathrm{~F}$ & 8 & 20 & $3.5 / 2 / 1$ & $2 / 1 / 0.5$ & None & 6 & Good \\
\hline 9 & M & 5 & 24 & $4.5 / 3.5 / 1.5$ & $3 / 2 / 0.5$ & None & 10 & Moderate \\
\hline 10 & $\mathrm{~F}$ & 6 & 16 & $5 / 3.5 / 2.5$ & $1 / 1.5 / 1$ & None & 8 & Excellent \\
\hline 11 & $\mathrm{~F}$ & 2.5 & 32 & $8 / 7 / 3$ & $2 / 1.5 / 1$ & None & 10 & Excellent \\
\hline 12 & M & 3 & 12 & $2 / 3 / 0.5$ & $1 / 0.5 / 0$ & None & 9 & Excellent \\
\hline 13 & $\mathrm{M}$ & 2 & 32 & $7 / 6.5 / 2$ & $0 / 0 / 0$ & None & 8 & Excellent \\
\hline 14 & $\mathrm{~F}$ & 4 & 28 & $5 / 4 / 1$ & $1 / 0.5 / 0.5$ & None & 6 & Excellent \\
\hline 15 & M & 6 & 20 & $3 / 3 / 0.5$ & $1 / 1.5 / 0$ & None & 6 & Good \\
\hline 16 & $\mathrm{~F}$ & 9 & 24 & $4 / 4 / 2$ & $1 / 0.5 / 1$ & None & 8 & Excellent \\
\hline 17 & $\mathrm{~F}$ & 7 & 24 & $5 / 5 / 2$ & $2 / 2 / 0.5$ & None & 12 & Good \\
\hline 18 & M & 5 & 12 & $2.5 / 2.5 / 0.5$ & $1 / 0.5 / 0$ & None & 12 & Excellent \\
\hline 19 & M & 3 & 16 & $2 / 2 / 0.5$ & $0 / 0 / 0$ & None & 9 & Excellent \\
\hline 20 & $\mathrm{~F}$ & 4.5 & 20 & $2.5 / 1.5 / 1$ & $0 / 0 / 0$ & None & 8 & Excellent \\
\hline 21 & $\mathrm{~F}$ & 3.5 & 16 & $2 / 1.5 / 0.5$ & $0.5 / 0.5 / 0$ & None & 6 & Good \\
\hline 22 & $\mathrm{~F}$ & 9 & 28 & $4 / 4.5 / 2$ & $2 / 2 / 0.5$ & None & 7 & Moderate \\
\hline
\end{tabular}

at Data presented a length/width/depth. IH, infantile hemangioma; M, male; F, female.

Table II. Heart rate and blood pressure at baseline and during the propranolol and timolol maleate treatment initiation period (mean \pm standard deviation).

\begin{tabular}{lrrrr}
\hline Parameter & \multicolumn{1}{c}{ Baseline } & \multicolumn{1}{c}{ Day 1 } & Day 2 & Day 3 \\
\hline Heart rate (beats per min) & $127.1 \pm 11.5$ & $124.0 \pm 15.6$ & $124.3 \pm 13.4$ & $125.3 \pm 14.8$ \\
SBP (mmHg) & $85.4 \pm 13.3$ & $84.6 \pm 17.1$ & $85.5 \pm 16.6$ & $85.0 \pm 18.2$ \\
DBP (mmHg) & $57.5 \pm 10.2$ & $58.3 \pm 12.6$ & $57.1 \pm 11.2$ & $56.9 \pm 9.7$ \\
\hline
\end{tabular}

SBP, systolic blood pressure; DBP, diastolic blood pressure.

No infants were withdrawn from the treatment study due to side effects. In total, 22 infants exhibited a decreased heart rate, blood pressure and rate of breathing after starting the treatment. However, all these signs returned to normal after propranolol had been administered for $>12 \mathrm{~h}$ ( $\mathrm{P}>0.05$; Table II), and no patients required additional treatment. No severe gastrointestinal adverse reactions occurred.

\section{Discussion}

Infantile parotid proliferating hemangiomas, which are the most common parotid tumors, occurred around 1 year after birth, accounting for $>50 \%$ parotid gland tumors in infants (11).
Hemorrhage, ulceration, infection and external auditory canal compression are the main complications of the tumor. Facial hemangiomas can cause serious psychological issues in the affected patients. Positive intervention rather than observation should be therefore be adopted, and appropriate treatment should be provided according to the different growth phases of the hemangiomas (12).

At present, the treatment methods for IH are conservative rather than surgical, and include as drug and laser therapies. Common drugs for the treatment of hemangioma are corticosteroids, and anticancer drugs, such as interferon and imiquimod (13-18), but these methods lead to different degrees of side effects. The only suitable treatment for early superficial 
hemangiomas is laser therapy (19). With regard to the surgical treatment of parotid region hemangiomas, there have been various proposals and the optimal surgical duration is uncertain. The surgical treatment must be selected carefully due to complications such as temporary paralysis, recurrence, salivary fistula, hematoma, auriculotemporal nerve syndrome, facial nerve injury and scarring (20).

Hemangiomas can be divided into three types according to the depth of their locations: Superficial hemangioma located in the papillary dermis, deep hemangioma located in the reticular dermis and subcutaneous tissue, and mixed hemangioma, which is a mixture of superficial and deep components (21). In the Department of Oral and Maxillofacial Surgery in the Hospital of Stomatology, personalized treatment options are used based on the hemangioma site, size and depth, among other factors, in order to obtain the best treatment effect (22). Currently, drug treatment is the preferred treatment of IHs. In 2008, Léauté-Labrèze et al first reported the use propranolol for the treatment of IH, and achieved good results (22). This study soon attracted the attention of scholars from all over the world, which triggered a series of associated studies on propranolol in the treatment of IH $(8,11,22,23)$. Propranolol is a non-selective $\beta$-adrenergic antagonist, whose treatment effect on $\mathrm{IH}$ is verified. Compared with the traditional corticosteroid therapy, it has better tolerability, less adverse reactions and greater efficiency (23-25). Timolol maleate is a non-selective potent $\beta$-adrenergic antagonist ( $\beta 1$ and $\beta 2$ ) that has been mainly used for the clinical treatment of hypertension, angina pectoris, tachycardia and glaucoma (26). The predominant adverse effects include hypotension, hypoglycemia, bronchospasm and local pruritus. Timolol was first used for glaucoma in the United States in 1978. It is safe for the treatment of the pediatric population, and has been used for glaucoma as a first-line medicine by pediatric ophthalmologists for $>30$ years (27). Timolol, as a type of ophthalmic drug, causes little irritation to local tissues, and its effect can only be observed in certain regions, with little systemic reaction, so the application of timolol maleate as a topical medication is extremely safe (28). Numerous clinical studies have demonstrated that treatment with propranolol is effective for both deep and superficial hemangiomas. In addition, the treatment response to oral propranolol is better for deep IHs than superficial IHs. Generally, timolol meleate is a highly effective treatment for superficial lesions. Therefore, combined treatment with oral propranolol and topical timolol maleate has been developed for mixed and superficial lesions, and oral propranolol is used to treat deep lesions (29).

No uniform safe dosage standard exists for the treatment of hemangioma using propranolol, however, according to domestic studies (30-33) and our considerable clinical experience, we believe that $1.0 \mathrm{mg} / \mathrm{kg}$ propranolol for patients $<3$ months old and $1.5 \mathrm{mg} / \mathrm{kg}$ propranolol for patients $>3$ months old is a safe dosage. An infant should, however, undergo a detailed general examination prior to this prescription. Furthermore, all infants should be hospitalized as an inpatient under observation for 3-5 days after the initial treatment, and the blood pressure, heart rate and adverse reactions should be closely monitored.

In 2010, Guo and $\mathrm{Ni}$ (34) described the case of a 4-month-old infant with superficial capillary hemangioma of the eyelid, and became the first study to report a successful outcome subsequent to the use of timolol solution; this success was subsequently reinforced by a series of other studies. In 2011, Pope and Chakkittakandiyil reported 6 cases of IHs treated with timolol in which the symptoms improved significantly (35). Li et al reported 25 cases of children with hemangiomas who were administered $0.5 \%$ topical timolol maleate, resulting in a clear positive effect. According to the related literature, the pharmacological effects of timolol are 8 times higher than propranolol (36). Therefore, the oral dose of propranolol can be reduced while topically using timolol maleate, therefore ensuring drug safety and reducing complications.

Despite the strong effects of propranolol and timolol maleate for the treatment of $\mathrm{IH}$, the mechanism of action remains unknown (37). Vasoconstriction may be responsible for the early effects on the color of the hemangioma due to the decreased release of nitric oxide. Growth arrest is attributable to the blocking of proangiogenic signals, including vascular endothelial growth factor, basic fibroblast growth factor, matrix metalloproteinases and endothelial nitric oxide synthase (38).

In the present study, attention was focused on the use of topical timolol maleate combined with oral propranolol for the treatment of parotid IHs. Good results were achieved using this combined treatment, which resulted in clear curative effects, with reduced complications. On the whole, as a quicker, safe and effective treatment, combined treatment with topical timolol maleate and oral propranolol for the treatment of parotid IHs should become the preferred therapeutic option.

\section{References}

1. Phung TL, Hochman M and Mihm MC: Current knowledge of the pathogenesis of infantile hemangiomas. Arch Facial Plast Surg 7: 319-321, 2005

2. Yuan WL, Jin ZL, Wei JJ, Liu ZY, Xue L and Wang XK: Propranolol given orally for proliferating infantile haemangiomas: Analysis of efficacy and serological changes in vascular endothelial growth factor and endothelial nitric oxide synthase in 35 patients. Br J Oral Maxillofac Surg 51: 656-661, 2013.

3. Mulliken JB and Glowacki J: Hemangiomas and vascular malformations in infants and children: A classification based on endothelial characteristics. Plast Reconstr Surg 69: 412-422, 1982.

4. Buckmiller LM, Richter GT and Suen JY: Diagnosis and management of hemangiomas and vascular malformations of the head and neck. Oral Dis 16: 405-418, 2010.

5. Enjolras $\mathrm{O}$ and Gelbert F: Superficial hemangiomas: Associations and management. Pediatr Dermatol 14: 173-179, 1997.

6. Liu X, Tai M, Qin Z, Li K and Ge C: Clinical analysis for treatment of 1,080 cases of infantile hemangiomas with oral propranolol. Zhonghua Yi Xue Za Zhi 94: 1878-1881, 2014 (In Chinese).

7. Waner M and Suen JY: Management of congenital vascular lesions of the head and neck. Oncology (Williston Park) 9: 989-994, 997; discussion 998 passim, 1995.

8. Malik MA, Menon P, Rao KL and Samujh R: Effect of propranolol vs prednisolone vs. propranolol with prednisolone in the management of infantile hemangioma: A randomized controlled study. J Pediatr Surg 48: 2453-2459, 2013.

9. Haggstrom AN, Drolet BA, Baselga E, Chamlin SL, Garzon MC, Horii KA, Lucky AW, Mancini AJ, Metry DW, Newell B, et al: Prospective study of infantile hemangiomas: Clinical characteristics predicting complications and treatment. Pediatrics 118: 882-887, 2006.

10. Achauer BM, Chang CJ and Vander Kam VM: Management of hemangioma of infancy: Review of 245 patients. Plast Reconstr Surg 99: 1301-1308, 1997.

11. Mantadakis E, Tsouvala E, Deftereos S, Danielides V and Chatzimichael A: Involution of a large parotid hemangioma with oral propranolol: An illustrative report and review of the literature. Case Rep Pediatr 2012: 353812, 2012.

12. Zheng JW: Infantile hemangiomas: Seldom wait and see. China Journal of Oral and Maxillofacial Surgery 10: 163-164, 2012 (In Chinese). 
13. Bennett ML, Fleischer AB Jr, Chamlin SL and Frieden IJ: Oral corticosteroid use is effective for cutaneous hemangiomas: An evidence-based evaluation. Arch Dermatol 137: 1208-1213, 2001.

14. Gangopadhyay AN, Sharma SP, Gopal SC, Gupta DK, Panjawani K and Sinha JK: Local steroid therapy in cutaneous hemangiomas. Indian Pediatr 33: 31-33, 1996.

15. Muir T, Kirsten M, Fourie P, Dippenaar N and Ionescu GO: Intralesional bleomycin injection (IBI) treatment for haemangiomas and congenital vascular malformations. Pediatr Surg Int 19: 766-773, 2004.

16. Omidvari S, Nezakatgoo N, Ahmadloo N, Mohammadianpanah $\mathrm{M}$ and Mosalaei A: Role of intralesional bleomycin in the treatment of complicated hemangiomas: Prospective clinical study. Dermatol Surg 31: 499-501, 2005.

17. Enjolras O, Brevière GM, Roger G, Tovi M, Pellegrino B, VarottiE, Soupre V, Picard A and Leverger G: Vincristine treatment for function- and life-threatening infantile hemangioma. Arch Pediatr 11: 99-107, 2004 (In French).

18. Ezekowitz RA, Mulliken JB and Folkman J: Interferon alfa-2a therapy for life-threatening hemangiomas of infancy. $\mathrm{N}$ Engl J Med 326: 1456-1463, 1992.

19. Hochman A, Mascareno A: Management of nasal hemangiomas. Arch Facial Plast Surg 7: 295-300, 2005.

20. Hamou C, Diner PA, Dalmonte P Vercellino N, Soupre V, Enjolras O, Vazquez MP and Picard A: Nasal tip haemangiomas: Guidelines for an early surgical approach. J Plast Reconstr Aesthet Surg 63: 934-939, 2010.

21. Zheng JW, Zhou GY, Wang YA and Zhang ZY: Management of head and neck hemangiomas in China. Chin Med J (Engl) 121: 1037-1042, 2008.

22. Léauté-Labrèze C, Dumas de la Roque E, Hubiche T, Boralevi F, Thambo JB and Taïeb A: Propranolol for severe hemangiomas of infancy. N Engl J Med 358: 2649-2651, 2008.

23. Price CJ, Lattouf C, Baum B, McLeod M, Schachner LA Duarte AM and Connelly EA: Propranlol vs corticosteroids for infantile hemangiomas: A multicenter retrospective analysis. Arch Dermatol 147: 1371-1376, 2011.

24. Storch CH and Hoeger PH: Propranolol for infantile haemangiomas: Insights into the molecular mechanisms of action. Br J Dermatol 163: 269-274, 2010.

25. Ribatti D: The crucial role of vascular permeability factor/vascular endothelial factor in angiogenesis: A historical review. Br J Haematol 128: 303-309, 2005.
26. Ye XX, Jin YB, Lin XX, Ma G, Chen XD, Qiu YJ, Chen H and $\mathrm{Hu}$ XJ: Topical timolol in the treatment of periocular superficial infantile hemangiomas: A prospective study. Zhonghua Zheng Xing Wai Ke Za Zhi 28: 161-164, 2012 (In Chinese).

27. Coppens G, Stalmans I, Zeyen T and Casteels I: The safety andefficacy of glaucoma medication in the pediatric population. J Pediatr Ophthalmol Strabismus 46: 12-18, 2009.

28. Guo S and Ni N: Topical treatment for capillary hemangioma of the eyelid using beta-blocker solution. Arch Ophthalmol 128: 255-256, 2010

29. Prey S, Voisard JJ, Delarue A,Lebbe G, Taïeb A,Leaute-Labreze C and Ezzedine K: Safety of propranolol therapy for severe infantile hemangioma. JAMA 315: 413-415, 2016.

30. Pope E and Chakkittakandiyil A: Topical timolol gel for infantile hemangiomas: A pilot study. Arch Dermatol 146: 564-565, 2010.

31. Xu Y, Xue L, Wei J, Lei B, Liu Z and Wang X: Oral propranolol treatment for infants with proliferating hemangiomas: Clinical analysis of 35 cases. Zhongguo Kouqiang He Mian Waike Zazhi 10: 159-162, 2012 (In Chinese).

32. Zheng JW, Zhou Q, Yang XJ, Wang YA, Fan XD, Zhou GY, Zhang ZY and Suen JY: Treatment guideline for hemangiomas and vascular malformations of the head and neck. Head Neck 32: 1088-1098, 2010

33. Zheng JW: Comment on efficacy and safety of propranolol in the treatment of parotid hemangioma. Cutan Ocul Toxicol 30: 333-334, 2011.

34. Xu DP, Cao RY, Tong S: Topical timolol maleate for superficial infantile hemangiomas: an observational study. J Oral Maxillofac Surg 73: 1089-1094, 2015.

35. Chan H, Mckay C, Adam S and Wargon O: RCT of timolol maleate gel for superficial infantile hemangiomas in 5-to 24-week-olds. Pediatrics 131: e1739-e1747, 2013.

36. Li G, Xu DP, Tong S, Xue L, Sun NN and Wang XK: Oral Propranolol With Topical Timolol Maleate Therapy for Mixed Infantile Hemangiomas in Oral and Maxillofacial Regions. J Craniofac Surg. 27: 56-60, 2016.

37. Storch $\mathrm{CH}$ and Hoeger PH. Propranolol for infantile hemangiomas: Insights into the molecular mechanisms of action. Br J Dermatol 163: 269-274, 2010

38. Itinteang T, Brasch HD, Tan ST and Day DJ: Expression of components of the renin-angiotensin system in proliferating infantile hemangioma may account for the propranolol-induced accelerated involution. J Plast Reconstr Aesthet 64: 759-765, 2010. 